OPEN ACCESS

Edited by:

Rui Matos,

Life Quality Research Centre (CIEQV),

Portugal

Reviewed by:

Giuseppe Mannino

Libera Università Maria SS. Assunta,

Italy

*Correspondence:

Zhi Yang

yangzy2@student.unimelb.edu.au

Specialty section:

This article was submitted to

Educational Psychology,

a section of the journal

Frontiers in Education

Received: 15 January 2022

Accepted: 11 February 2022

Published: 07 March 2022

Citation:

Yang Z, Bai Y and Wei M (2022)

The Importance of Creativity

in the Sportification of Breakdance.

Front. Educ. 7:855724.

doi: 10.3389/feduc.2022.855724

\section{The Importance of Creativity in the Sportification of Breakdance}

\author{
Zhi Yang ${ }^{1 *}$, YuJie Bai ${ }^{1}$ and MingTao Wei ${ }^{2}$ \\ ${ }^{1}$ Melbourne Graduate School of Education, The University of Melbourne, Parkville, VIC, Australia, ${ }^{2}$ Teachers College, \\ Changshu Institute of Technology, Suzhou, China
}

Many historical works have attempted to reveal the process of the sportification of physical activity that originated in the eighteenth century. The process of sportification can be divided into three basic mechanisms: The institutionalization of practices, the formalization of standards, and the specialization of roles. Marginalized and discriminated lower-class American youths first used breakdancing to express their emotions. Nowadays, it has been announced by the International Olympic Committee as part of the Paris 2024 Olympic program in Paris, France. Therefore, this change may also further the specialization of breakdance teaching. In addition, this mini-review believes that it is necessary for breakdancing teachers, students, and judges to have a clear understanding of creativity, as it is often used as an essential scoring criterion in breakdancing competitions. This mini-review also shows the origins and evolution of breakdance. Cipher as a form of artistic communication produced the domino effect, which promoted the widespread popularity of breakdance worldwide. Creativity has also driven the evolution of breakdance moves. Finally, this article discusses the advantages and examples of the Four $\mathrm{C}$ models and suggests a set of methods for breakdance teachers to foster creativity in breakdance students.

Keywords: creativity, breakdance, hip-hop culture, teaching methods, sportification, cipher

\section{INTRODUCTION}

Breakdance as a creative dance originated from the American hip-hop cultural movement in the 1970s. The lowest classes of American society initially used breakdancing to express their emotions (Forman, 2002). However, nowadays, breakdancing has been announced by the International Olympic Committee (IOC) for inclusion in the 2024 Paris Olympics (IOC, 2019). This change could indicate a new development opportunity for the breakdancing instruction industry. One reason is that an increasing number of commercial companies and advertising agencies will be investing money in the breakdancing industry (Li and Vexler, 2019; Zuma and Rooijackers, 2020). This article derives from the author's ongoing thinking on two questions about the breakdancing teaching industry. One question needs to be asked. When breakdancing is included in France's 2024 Paris Olympic event, how do breakdancing teachers train their students to win? One possible explanation for this is that creative students are more likely to win breakdancing competitions. One reason is that creativity is often used as a crucial scoring criterion in breakdancing competitions (Shimizu and Okada, 2018). 
The two authors of this article visited many breakdance studios in China. They shared their teaching methods with many breakdance teachers. An interesting finding was that the execution of the dance movements demonstrated by almost all the students was similar; even the emotions and facial expressions were highly similar. This phenomenon may indicate that these children do not have a high level of creativity in dance. Essentially, the most distinctive feature of creative dance is that the expressive aspect is more important than the functional aspect (Bergmann, 1992); it is an expression of the inner self through physical movement, rather than imitation and copying the moves of others (Bergmann, 1992). Heyes (2011) argued that students' conscious or unconscious copying of the content presented by the teacher could lead to imitation. This phenomenon is widespread, especially in dance learning, and students' lack of self-expression and creativity is equally seen as a problem to be addressed by other dance education researchers (Giguere, 2011; Foley, 2016; Pürgstaller, 2021).

These persistent and truly wicked phenomena of imitation or copying, and the equally persistent concerns expressed by teachers, frame a second serious question for breakdance teachers: What is the way or better way for breakdance teachers to foster their students' creativity in dance? Lucas (2016) believed that students' level of creativity is closely related to the level of creativity of teachers and that if teachers do not understand creativity, they probably will not develop the creativity of learners. There are different definitions of creativity. Common definitions of creativity are usually usefulness and originality (Runco and Albert, 2010). In the case of usefulness, it usually refers to whether the things created by people satisfy their physical and psychological needs (Runco and Albert, 2010). For example, when people creatively design and participate in physical activity, their memory and attention can be effectively improved (Mannino et al., 2019). The second part of this article also provides a new case for the usefulness of creativity. For example, numerous literature reviews suggest that the birth of breakdancing represented a vision of youth from the underclass of American society against violence and discrimination (Blagojević, 2009; Langnes and Fasting, 2016; Bode Bakker and Nuijten, 2018). As a critical element of hiphop culture, breakdance, with its philosophy of peace, unity, love, and fun, has positively impacted young people worldwide (Li and Vexler, 2019).

In addition, according to Clements and Redding (2020), students' creativity in dance can be developed through performance, technique, and theoretical study. The third part uses the concept of creativity levels to discuss how to breakdance teachers can foster children's creativity in their teaching and provides a new case study for Clements' argument. In other words, if our research can offer breakdance teachers a way to foster creativity in their students, then we can help more children create unique and attractive choreography in their future dance careers. Furthermore, if Chinese breakdance students can make more outstanding breakdance works, then we can lay the groundwork for a future research question: whether breakdance, as a product of American hip-hop culture, can be adapted to the traditional cultures of other countries.

\section{THE EVOLUTION AND SPREAD OF BREAKDANCING}

As stated in the introduction, breakdance as a creative dance originated from the American hip-hop cultural movement in the 1970s. As racial discrimination and social segregation continue to spread, this has led to performing breakdancing as a way for young people to construct identity and express their emotions. According to Evans Pim (2018), breakdancing became an alternative in the past for young people to address physical violence with dance moves, and today, it still plays positive effects in preventing violence. A new form of artistic exchange was born when youths from the lower classes of society and those who suffered from discrimination started to come together to share the joy of hip-hop culture. At the time, older hip-hop artists referred to this form of art sharing as cipher and battle (Li and Vexler, 2019).

Before the advent of the internet and self-media applications, cipher became the primary method of communication for promoting hip-hop culture and events (Li and Vexler, 2019). DJs use music to cipher, graffiti artists use graffiti to cipher, dancers use dance moves to cipher, and so do all the elements of hiphop. Those boys and girls who use dance moves to cipher are often called b-boys, b-girls, or breakers (Chew and Mo, 2019). Cipher as a form of art sharing is often seen at hip-hop parties and DJ's music shows, where breakers usually move their body regularly to the beat of the DJ's music, creating a dance called breakdance. Gottschild (1996) noted that breakdance originated as a creative dance because breakers combine dance moves with music to express their emotions and thoughts. In hip-hop parties, the DJ can provide the beats, the MC provides the lyrics and the breaker shows the dance moves, these three elements of hip-hop combine to create a uniquely artistic atmosphere.

Third, creativity also promotes the development of breakdance. More specifically, the older breakers used their ideas and wisdom to create diverse breakdance moves. For instance, b-boy (and UCLA dance expert) Ken Swift, a famous breaker of the older generation, created a breakdance move called crazy legs by moving and spinning his body and feet rapidly across the floor (Breaking history, 2021). Even today, these moves, created by the older generation of breakers, can still be found in various breakdance competitions. For young dancers who are eager to advance in their dance careers, they can attend a cipher to learn from the older generation of experienced breakers (Li and Vexler, 2019). The older breakers also advise the new generation to create their dance style based on the original moves, rather than copying others' moves. One reason is that the philosophy of hip-hop art encourages artists to be creative (Lora, 2012). Therefore, we should pay tribute to the older generation of dancers who used their wisdom to create different breakdancing moves. 
With the popularity of hip-hop culture in the 1970s, American breakers began to share their dance with tourists in New York. Some breakers spread the dance during their travels, and a new cipher emerged around the world (Li and Vexler, 2019). Another part of breakdance has been spread worldwide by media companies through online videos (Burton, 2005). When a breaker starts a cipher in a new place, other interested people learn how to join the cipher. Local breakers began to grow rapidly and practice in other areas nearby, forming their dance teams and meeting other teams for ciphers. Cipher produced a domino effect as the core of promoting hip-hop cultural events (Li and Vexler, 2019). Nowadays, breakers worldwide are also using the global cipher to keep spreading breakdance, which is the history of breakdance.

Many historical works have attempted to reveal the process of the sportification of physical activity that originated in the eighteenth century (Collinet et al., 2013; Li and Vexler, 2019). Collinet et al. (2013) argued that the process of sportification can be divided into three basic mechanisms: the institutionalization of practices, the formalization of standards, and the specialization of roles (coach, player, and judge). The formalization of standards usually occurs with the implementation of competitive events, such as setting rules based on the player's age, gender, and level (Collinet et al., 2013). As mentioned in the introduction, breakdance was first used by marginalized and discriminated lower-class American youths to express their emotions, and nowadays, it has been announced by the International Olympic Committee as part of the Paris 2024 Olympic program in Paris France. Therefore, this change may also further the specialization of breakdance teaching. It is necessary for breakdance teachers to understand how to foster creativity in their students because creativity is usually a criterion for scoring in breakdance competitions (Shimizu and Okada, 2018). In the next section, this article will discuss the impact of creativity on breakdance competition and teaching.

\section{THE IMPACT OF CREATIVITY ON BREAKDANCE TEACHING AND COMPETITION}

All dance genres emphasize the importance of creativity in their philosophy (Butterworth, 2004; Farrer, 2014), and breakdance is no exception, encouraging people to create different dance moves in cipher. Breakdance is so attractive that even the Olympics wish to add it to the program. The International Olympic Committee announced that a competitive event called breakdance would be added to the 2024 Olympic Games in Paris, France (IOC, 2019). For breakdance teachers, it is essential to understand creativity because it may affect the performance of students in breakdance competitions. For instance, in breakdancing competitions, creativity usually accounts for the highest scores in the four scoring criteria (i.e., fundamentals, dynamics, execution of moves, and creativity) (Shimizu and Okada, 2018). The literature is voluminous, and there is a general tendency to fail to define creativity (Torrance, 1988; Plucker et al., 2004). One interesting finding is that common creativity is usually defined in some literature as usefulness and originality (Mumford and
Gustafson, 1988; Jones et al., 2016). However, these definitions have some limitations, such as they are more product-oriented. In other words, these definitions may be inappropriate when used to explain creativity in dance. Torrance (1988) supports this view that creativity can not be defined precisely, but a common understanding of creativity is needed when it becomes an assessment criterion. Therefore, if judges, teachers, or athletes do not have a common understanding of the definition of creativity, then this phenomenon is likely to affect breaker's competition scores.

Secondly, if teachers understand creativity, then they are likely to teach students how to use creative thinking to integrate with dance movement. A fact clearly documented by authors, such as Foley (2016) and Shimizu and Okada (2018), is that creative teachers usually teach their students ideas for choreography (e.g., changes in the direction of dance movements, sequential combinations of dance elements, control of power, etc.) and even use deliberate practice theory to help learners improve the elaboration of their dance movements. The psychological view is that one of the criteria for assessing creativity is elaboration (Clements and Redding, 2020), which refers to the degree to which an idea is developed and refined (Goff, 2002). If breakdance teachers have a good understanding of creativity, then they can more effectively foster learners' creativity.

Finally, Hattie (2008) argued that creativity is positively correlated with students' learning effectiveness. According to Hattie (2008), if breakdance teachers can develop a creative learning program, then creative learning plans are likely to improve students' effectiveness of learning dance. Foley's (2016) research provides a new case for our argument. In Foley's (2016) b-baby project, she differentiated and explained the movement structures of breakdance (e.g., top rock, footwork, transition, power move, and freeze) and sorted each movement from easy to difficult level. The purpose of this approach is to better adapt to the physical conditions of students of different ages and to set a flexible after-school training schedule, which in turn increases the efficiency of students' learning. Similarly, OFSTED (2010) also argued that creative learning plans could improve students' learning efficiency and attendance in dance classes. Therefore, developing a creative learning plan is essential for breakdance teachers and students. This section discusses the impact of creativity in breakdance competition and teaching. The next section of this article will discuss how to breakdance teachers can enhance children's creativity from creativity level theory. As noted by Clements and Redding (2020), creativity in dance can be developed through technique and theory.

\section{THE FOUR C MODEL OF CREATIVITY IN BREAKDANCE TEACHING}

Kaufman and Beghetto (2009) define creativity as having four levels: Mini-C creativity (subjectively recognized creativity), Little-C creativity (creativity recognized from others), Pro$\mathrm{C}$ creativity (creativity classified as a novel and significant contribution by experts in the area), and Big- $\mathrm{C}$ creativity (major creative achievements that only a few people can achieve). Based 
on the concept of creativity levels, breakdance teachers should first ensure children's creativity reaches the mini-c and little-c levels and then help students to reach pro-c creativity and bigc creativity levels. One reason is that this process follows the physical and mental development of the child. Unlike adults, children have not formed a clear perception of the rules and definitions of dance, and they can live freely and happily without being influenced by the opinions of others (Pürgstaller, 2021).

Secondly, in terms of little-c creativity (creativity that is recognized as such by someone else), breakdance teachers should encourage and support children to explore the integration of dance movements with personal emotional expression and provide materials that can be choreographed because the focus of the creative dance is to explore the possibilities of personal, expressive movement. Foley's (2016) baby project gives an excellent example of our argument; for instance, breakdance teachers can encourage children to show like superheroes during the dance, making the dance moves more dynamic. During the improvisation process, teachers should give positive encouragement and feedback, regardless of whether the children's presentation is good or bad (e.g., lack of fluency in movement and anxiety). Similarly, Starko (1999) argued that finding a problem, identifying a question to answer, or investigating an area can be a crucial component of creative productivity.

Finally, Giguere (2011) argued that the social aspects of dance creation are essentially collaborative. Collaboration is shared creativity and discovery between two or more people with complementary skills, interacting to create a shared understanding that no one had previously possessed or might have known on their own (Moran et al., 2003). If breakdance teachers divide students into groups and require them to follow a set routine to choreograph, pupils may not collaborate. Therefore, breakdance teachers can support children to work in groups and share and exchange ideas, laying the foundation for developing children's mini-c creativity (subjectively recognized creativity).

\section{CONCLUSION}

When breakdance is included as a competitive sport in the 2024 Olympic Games in Paris, France, breakdance teachers and

\section{REFERENCES}

Bergmann, S. (1992). The process/product dichotomy and its implications for creative dance. J. Aesthetic Educat. 26, 103-108. doi: 10.2307/333 2928

Blagojević, G. (2009). Belgrade breakdance girl: Breaking gender-specific stereotypes with dance. Гласник Етнографског института СНАY 57, 1924. doi: 10.2298/gei0902019b

Bode Bakker, M., and Nuijten, M. (2018). 'When breaking you make your soul dance'Utopian aspirations and subjective transformation in breakdance. Identities 25, 210-227. doi: 10.1080/1070289X.2017. 1400275

Breaking history (2021). KENQ13 SWIFT (7Gems) 2018 V1 Battle of the Gods Recap (2018). [Video]. YouTube. Available online at: https://www.youtube.com/ watch?v=u5NxDTuZtrw (accessed March 19, 2021).

Burton, G. (2005). Media and society : critical perspectives. Omaha: Open University Press. judges need to have a common understanding of the definition of creativity. This is because creativity is usually used as one of the scoring criteria for breakdance competitions. This article discusses the advantages and examples of the four $\mathrm{C}$ models. In terms of teaching methods, breakdance teachers should first ensure children's creativity reaches mini-c and little-c levels and then help students achieve pro-c and big-c creativity levels. One reason is that, unlike adults, children have not developed a clear perception of dance rules and the definition of creativity. In terms of Mini-C creativity, breakdance teachers can support children working in groups and sharing and exchanging ideas with each other, laying the foundation for developing children's creativity (subjectively recognized creativity) because the social aspects of dance creation are essentially collaborative. The second aim is to describe the development and evolution of breakdance. To be specific, cipher as a form of hip-hop art communication produced a domino effect, which contributed to the widespread popularity of breakdance worldwide. Creativity has also contributed to the emergence of different styles of breakdance moves. A limitation of this article is that it does not adequately describe the divergence between breakdance as a product of the American hip-hop cultural movement and other national cultures. Despite its limitations, the article indicates that creativity positively influences the teaching and competition of breakdance.

\section{AUTHOR CONTRIBUTIONS}

$\mathrm{ZY}$ and $\mathrm{YB}$ designed and researched the article and wrote the manuscript. MW as an expert in sports reviewed the manuscript. All authors contributed to the article and approved the submitted version.

\section{ACKNOWLEDGMENTS}

We thank everyone who agreed to be interviewed and share their knowledge, as well as all the young and old B-Boys and B-Girls around the world, especially the veterans who created this dance because hip-hop has been the cultivation of all our hopes and dreams.

Butterworth, J. (2004). Teaching choreography in higher education: a process continuum model. Res. Dance Educat. 5, 45-67. doi: 10.1080/ 1464789042000190870

Chew, M. M.-T., and Mo, S. P. S. (2019). Towards a chinese hip-hop feminism and a feminist reassessment of hip-hop with breakdance: B-girling in Hong Kong, Taiwan and China. Asian Stud. Rev. 43, 455-474. doi: 10.1080/10357823.2019. 1631256

Clements, L., and Redding, E. (2020). Creativity in higher education contemporary dance. J. Dance Educat. 20, 88-98. doi: 10.1080/15290824.2019.1572155

Collinet, C., Delalandre, M., Schut, P.-O., and Lessard, C. (2013). Physical practices and sportification: Between institutionalisation and standardisation. The example of three activities in france. Int. J. History Sport 30, 989-1007. doi: 10.1080/09523367.2013.782538

Evans Pim, J. (2018). Preventing violence through hip hop: an evolutionary perspective. J. Peace Educat. 15, 325-344. doi: 10.1080/17400201.2018.1535474

Farrer, R. (2014). The creative dancer. Res. Dance Educat. 15, 95-104. doi: 10.1080/ 14647893.2013 .786035 
Foley, C. G. (2016). From b-girl to b-baby: Constructing a breakin' pedagogy. J. Dance Educat. 16, 62-66. doi: 10.1080/15290824.2015.1081206

Forman, M. (2002). The'hood Comes first: Race, Space, and Place in Rap and Hip-Hop. Middletown: Wesleyan University Press.

Giguere, M. (2011). Dancing thoughts: an examination of children's cognition and creative process in dance. Res. Dance Educat. 12, 5-28. doi: 10.1080/14647893. 2011.554975

Goff, K. (2002). Abbreviated Torrance test for adults: Manual. Bensenville, IL: Scholastic Testing Service.

Gottschild, B. D. (1996). Digging the Africanist Presence in American Performance: Dance and Other Contexts (No.179). Westport, CT: Praeger.

Hattie, J. (2008). Visible Learning: A Synthesis Of Over 800 Meta-Analyses Relating To Achievement. Netherland: Routledge.

Heyes, C. (2011). Automatic imitation. Psychol. Bull. 137, 463-484.

IOC (2019). Breaking approved as one of four provisional sports for Paris 2024. Olympic News. Available online at: https://olympics.com/en/news/paris-2024provisional-breaking-climbing-surfing-skateboard (accessed 25 June 25, 2019).

Jones, C., Svejenova, S., Pedersen, J. S., and Townley, B. (2016). Misfits, mavericks and mainstreams: Drivers of innovation in the creative industries. Organiz. Stud. 37, 751-768. doi: 10.1177/0170840616647671

Kaufman, J. C., and Beghetto, R. A. (2009). Beyond Big and Little: The four c model of creativity. Rev. General Psychol. 13, 1-12. doi: 10.1037/a0013688

Langnes, T. F., and Fasting, K. (2016). Identity constructions among breakdancers. Int. Rev.Sociol. Sport 51, 349-364. doi: 10.1177/1012690214526402

Li, R. Z., and Vexler, Y. A. (2019). Breaking for gold: Another crossroads in the divergent history of this dance. Int. J. History Sport 36, 430-448. doi: 10.1080/ 09523367.2019.1615896

Lora (2012). Beats, Rhymes and Life. Creativity and Hip Hop. Available online at: https:/globalnoise.wordpress.com/2012/11/29/the-centrality-of-creativityin-hip-hop/ (accessed November 29, 2012).

Lucas, B. (2016). A five-dimensional model of creativity and its assessment in schools. Appl. Measur. Educat. 29, 278-290. doi: 10.1080/08957347.2016. 1209206

Mannino, G., Giunta, S., Montefiori, V., Tamanza, G., Iacolino, C., Novara, C., et al. (2019). Healthy lifestyle, well-being, physical activity, sport, and scholastic/academic performance: Interactions and connections. World Fut. 75, 462-479. doi: 10.1080/02604027.2019.1654772

Moran, S., John-Steiner, V., and Sawyer, R. (2003). Creativity in the making: Vygotsky's contemporary contribution to the dialectic of development and creativity. 61-90. doi: 10.1093/acprof:oso/9780195149005.003.0003

Mumford, M. D., and Gustafson, S. B. (1988). Creativity syndrome: Integration, application, and innovation. Psychol. Bull. 103, 27-43. doi: 10.1037/0033-2909. 103.1.27
OFSTED (2010). Learning: Creative approaches that raise standards. London: OFSTED London.

Plucker, J. A., Beghetto, R. A., and Dow, G. T. (2004). Why isn't creativity more important to educational psychologists? potentials, pitfalls, and future directions in creativity research. Educat. Psychol. 39, 83-96. doi: 10.1207/s15326985ep3 902_1

Pürgstaller, E. (2021). Assessment of creativity in dance in children: Development and validation of a test instrument. Creat. Res. J. 33, 33-46. doi: 10.1080/ 10400419.2020.1817694

Runco, M. A., and Albert, R. S. (2010). Creativity Research: A Historical View. Cambridge: Cambridge University Press.

Shimizu, D., and Okada, T. (2018). How do creative experts practice new skills? exploratory practice in breakdancers. Cogn. Sci. 42, 2364-2396. doi: 10.1111/ cogs. 12668

Starko, A. J. (1999). "Problem finding: A key to creative productivity," in Investigating creativity in youth: Research methods, eds A. S. Fishkin, B. Cramond, and P. Olszewski-Kubilius (Cresskill, NY: Hampton Press, Inc), 75-96.

Torrance, E. P. (1988). "The nature of creativity as manifest in its testing," in The nature of creativity: Contemporary psychological perspectives, ed. R. J. Sternberg, (Cambridge: Cambridge University Press), $43-75$.

Zuma, B., and Rooijackers, M. (2020). Uncovering the potential of urban culture for creative placemaking. J. Tourism Fut. 6, 233-237. doi: 10.1108/JTF-102019-0112

Conflict of Interest: The authors declare that the research was conducted in the absence of any commercial or financial relationships that could be construed as a potential conflict of interest.

Publisher's Note: All claims expressed in this article are solely those of the authors and do not necessarily represent those of their affiliated organizations, or those of the publisher, the editors and the reviewers. Any product that may be evaluated in this article, or claim that may be made by its manufacturer, is not guaranteed or endorsed by the publisher.

Copyright (c) 2022 Yang, Bai and Wei. This is an open-access article distributed under the terms of the Creative Commons Attribution License (CC BY). The use, distribution or reproduction in other forums is permitted, provided the original author(s) and the copyright owner(s) are credited and that the original publication in this journal is cited, in accordance with accepted academic practice. No use, distribution or reproduction is permitted which does not comply with these terms. 